\title{
Conformation and membrane interaction studies of the potent antimicrobial and anticancer peptide palustrin-Ca
}

\section{Patrick B. Timmons ${ }^{1}$, Chandralal M. Hewage ${ }^{1 \dagger}$}

${ }^{1}$ UCD School of Biomolecular and Biomedical Science, UCD Centre for Synthesis and Chemical Biology, UCD Conway Institute, University College Dublin, Dublin 4, Ireland

${ }^{\dagger}$ chandralal.hewage@ucd.ie

\begin{abstract}
Palustrin-Ca (GFLDIIKDTGKEFAVKILNNLKCKLAGGCPP) is a host defense peptide with potent antimicrobial and anticancer activities, first isolated from the skin of the American bullfrog Lithobates catesbeianus. The peptide is 31 amino acid residues long, cationic and amphipathic. Two-dimensional NMR spectroscopy was employed to characterise its three-dimensional structure in a $50 / 50 \%$ water $/ 2,2,2$ trifluoroethanol- $d_{3}$ mixture. The structure is defined by an $\alpha$-helix that spans between $\mathrm{Ile}^{6}-\mathrm{Ala}^{26}$, and a cyclic disulphide bridged domain at the C-terminal end of the peptide sequence, between residues 23 and 29 .

A molecular dynamics simulation was employed to model the peptide's interactions with sodium dodecyl sulphate micelles, a widely used bacterial membrane-mimicking environment. Throughout the simulation, the peptide was found to maintain its $\alpha$-helical conformation between residues $\mathrm{Ile}^{6}-\mathrm{Ala}^{26}$, while adopting a position parallel to the surface to micelle, which is energetically-favourable due to many hydrophobic and electrostatic contacts with the micelle.
\end{abstract}




\section{Acknowledgements}

$\mathrm{CH}$ is grateful to John O'Brien and Manuel Ruether at Trinity College Dublin for NMR facilities, University College Dublin for a Research Scholarship to PBT, ICHEC for access to supercomputer facilities. The solution structure of palustrin-Ca was deposited to the PDB at the RSCB with deposition code $7 \mathrm{P} 4 \mathrm{X}$.

\section{Introduction}

Host defence peptides (HDPs) are naturally occurring molecules that are secreted as part of the non-specific response of the innate immune system ${ }^{[1]}$. These molecules contribute to the immune system's antimicrobial response either by exerting direct antimicrobial activity, or by altering the host's immune response. HDPs are particularly prevalent in amphibians, with approximately one third of all known HDPs having been originally isolated from amphibians. Nonetheless, HDPs are a highly conserved part of the immune response, and have been found in all species of organisms, from humans to bacteria ${ }^{[2-5]}$.

As the number of documented cases of antimicrobial resistance to conventional small-molecule drugs continues to rise, interest in HDPs, which can exert their antimicrobial activity against both Gram-positive bacteria and Gram-negative bacteria without the development of resistance, continues to grow ${ }^{[6]}$. HDPs possess a number of additional advantages. They are more efficacious, selective and specific than small molecules, and are degraded to naturally occurring amino acids, which reduces the danger of unfavourable drug-drug interactions. HDPs are suitable for use both in combination with conventional drugs, and as standalone substitutes. The biological activities of HDPs, however, are not limited to bacteria. HDPs have also been demonstrated to possess antifungal, antiparasitic, antiviral and anticancer activities $^{[7]}$. Indeed, palustrin-Ca (GFLDIIKDTGKEFAVKILNNLKCKLAGGCPP) is reported to be the most potent known anticancer peptide, with an $\mathrm{IC}_{50}$ of $0.951 \mu \mathrm{g} / \mathrm{ml}$ against human gastric cancer SGC-7901 ${ }^{[8]}$.

Typically, HDPs are short, with a primary sequence length between 10-50 amino acid residues. Usually, HDPs are unstructured in aqueous solution, and only adopt a defined secondary structure upon contact with a biological membrane, or in a hydrophobic environment. The induced structures are predominantly $\alpha$-helical in nature, although other identified structures include $\beta$-sheet, mixed $\alpha-\beta$ and extended structures. A common feature of HDP structures are that they are typically amphipathic in nature, with a 
clear separation between the peptide's hydrophobic and polar or charged residues. Overall, HDP's are usually positively charged, although a number of negatively charged peptides have been isolated as well ${ }^{[9]}$. Indeed, increased positive charge, up to a certain extent, has been associated with greater antimicrobial activity ${ }^{[10,11]}$. Similarly, increased peptide hydrophobicity is associated with peptide hemolytic activity, and thereby represents another key feature which can be changed to modulate peptide selectivity ${ }^{[12,13]}$.

While HDPs are typically positively charged, anionic molecules such as lipopolysaccharides (LPS), phospholipids and teichoic acids are prevalent in prokaryotic cell membranes, which enables attractive electrostatic interactions between HDPs and their target bacterial cell membranes ${ }^{[14,15]}$. Similarly to prokaryotic membranes, the cell membranes of cancer cells are enriched in negative charge, unlike non-cancerous cell membranes which are neutral, which allows anticancer peptides to be selectively electrostatically attracted to cancer cells.

HDPs usually exert their bactericidal activity via disruption of the bacterial cell membrane, for which three main mechanisms of action have been described: the toroidal pore model, barrel-stave model and carpet model. All three membranolytic mechanisms of action are relatively non-specific, which is the reason why few cases of bacterial resistance to HDPs have been described $^{[16,17]}$. The initial step in all three mechanisms is the HDP binding of the target membrane, initially facilitated via the aforementioned electrostatic attraction, then via hydrophobic attraction. Eventually, a threshold peptide concentration is reached, which may be determined by the organism's capacity to repair its damaged cell membranes ${ }^{[18]}$, whereupon the mechanism proceeds via the pore-forming toroidal pore or barrel-stave models, or the non-pore-forming carpet model. The latter requires that the bilayer curvature is disrupted, thereby disintegrating the bacterial membrane. Under the toroidal pore model, the bacterial membrane is bent from the outer leaflet inwards, resulting in the formation of a transmembrane toroidal pore lined by the peptides and the membrane's lipid head groups ${ }^{[19,20]}$. The barrel-stave model, meanwhile, involves the peptides forming a transmembrane pore; its lumen is lined by the peptides' hydrophobic residues, and its exterior is composed of hydrophilic residues, which are in contact with the membrane's lipid headgroups. All the models of HDP activity culminate in the dissipation of the cross-membrane electrical potential and the leakage of cellular components.

Our laboratory has conducted structural studies on various amphibian $\mathrm{HDPs}$, including ranatuerin-2CSa ${ }^{[21]}, \mathrm{XT}-7^{[22]}$, alyteserin- $1 \mathrm{c}^{[23]}$, brevinin$1 \mathrm{BYa}{ }^{[24]}$ and its analogues ${ }^{[25]}$, maximin $3^{[26]}$ and maximin $1^{[27]}$. Palustrin-Ca (GFLDIIKDTGKEFAVKILNNLKCKLAGGCPP) is a 31 amino acid residue 
HDP first isolated from the skin of the American bullfrog Lithobates catesbeianus ${ }^{[8]}$. In common with other HDPs isolated from frogs belonging to the Ranidae family, it contains a cyclic disulphide bridged domain at the Cterminal end of the peptide sequence, between residues 23 and 29. Palustrin$\mathrm{Ca}$ is biologically interesting, as it non-hemolytic, and exhibits potent broadspectrum antibacterial activity, and as previously mentioned, very potent anticancer activity, with an $\mathrm{IC}_{50}$ of $0.951 \mu \mathrm{g} / \mathrm{ml}$ against human gastric cancer SGC-7901 ${ }^{[8]}$. In this work, palustrin-Ca's conformation and structural properties are elucidated using NMR spectroscopy, with an ensemble of model structures being determined. Additionally, the peptide's interactions with a membrane-mimetic are simulated using an atomistic molecular dynamics simulation.

\section{Materials and methods}

\subsection{Materials and NMR sample preparation}

The palustrin-Ca peptide ( $\mathrm{MW}=3304 \mathrm{~g} \mathrm{~mol}^{-1}$, purity >95\%) was purchased from ProteoGenix (Paris). $4.5 \mathrm{~g}$ of the peptide was dissolved in $0.6 \mathrm{~mL}$ of a $50 \%(\mathrm{v} / \mathrm{v}) \mathrm{TFE}-d_{3} / \mathrm{H}_{2} \mathrm{O}$ solution, resulting in a final peptide concentration of $2.27 \mathrm{mM}$. 3-trimethylsilyl propionic acid (TSP) and 2,2,2-trifluoroethanol $\left(\mathrm{TFE}-d_{3}\right)$ of analytical grade were obtained from Sigma-Aldrich (Ireland).

\subsection{NMR spectroscopy}

A Bruker Avance 600 NMR spectrometer with a $5 \mathrm{~mm}$ inverse probe head at a ${ }^{1} \mathrm{H}$ resonance frequency of $600.13 \mathrm{MHz}$ was used to perform a number of NMR experiments at a temperature of $298 \mathrm{~K}$. One-dimensional proton, 2D phase-sensitive total correlation spectroscopy (TOCSY) ${ }^{[28]}$, nuclear Overhauser effect spectroscopy (NOESY) ${ }^{[29]}$ and natural abundance ${ }^{1} \mathrm{H}_{-}{ }^{13} \mathrm{C}$ and ${ }^{1} \mathrm{H}-{ }^{15} \mathrm{~N}$ heteronuclear single quantum coherence spectroscopy $\left({ }^{1} \mathrm{H}-{ }^{13} \mathrm{C}-\mathrm{HSQC}\right)$ and ${ }^{1} \mathrm{H}_{-}{ }^{15} \mathrm{~N}-\mathrm{HSQC}{ }^{[30]}$ spectra were acquired, with relaxation delays of $2.5 \mathrm{~s}$, $2.0 \mathrm{~s}, 1.5 \mathrm{~s}, 1.0 \mathrm{~s}$ and $2.0 \mathrm{~s}$, respectively, and acquisition times of $3.4 \mathrm{~s}, 340$ ms, $280 \mathrm{~ms}, 170 \mathrm{~ms}$ and $100 \mathrm{~ms}$, respectively. Mixing times of $60 \mathrm{~ms}$ and 200 ms were used for the TOCSY and NOESY, respectively.

The ${ }^{1} \mathrm{H}$ spectral widths were $6.0 \mathrm{kHz}, 7.2 \mathrm{kHz}, 6.0 \mathrm{kHz}$ and $9.6 \mathrm{kHz}$, and the spectra were acquired with 4, 16, 32 and 64 transients for each of the 1024, 2048, 256 and $128 \mathrm{t} 1$ increments for the TOCSY, NOESY, ${ }^{1} \mathrm{H}_{-}{ }^{13} \mathrm{C}-$ HSQC and ${ }^{1} \mathrm{H}-{ }^{15} \mathrm{~N}-\mathrm{HSQC}$, respectively. The ${ }^{13} \mathrm{C}$ spectral width was $21.1 \mathrm{kHz}$ and the ${ }^{15} \mathrm{~N}$ spectral width was $10.9 \mathrm{kHz}$. All two-dimensional spectra were 
processed with the Bruker TopSpin program, version 4.0.6 (Bruker BioSpin, Germany), using the sine squared window function, and the ${ }^{1} \mathrm{H}$ signal of TSP was used as the chemical shift reference.

\subsection{Structure calculation}

The NMRFAM-SPARKY, version 3.131 ${ }^{[31]}$ was used to analyse the acquired NMR spectra and integrate the NOESY cross-peaks. The integrated peak volumes were exported, and the nuclear Overhauser effect (nOe) cross-peak intensities were calibrated using the CALIBA ${ }^{[32]}$ program, yielding a set of upper distance restraints. Protons that could not be stereospecifically assigned were treated as pseudoatoms. The set of obtained distance restraints was used as input to CYANA ${ }^{[33]}$, excluding those that represent fixed distances. A force constant of $1 \mathrm{~kJ} \mathrm{~mol}^{-1} \AA^{-2}$ was used to weight the distance restraints, from which one hundred structures were generated by CYANA ${ }^{[34]}$, and submitted to 20,000 steps of simulated annealing and 20,000 of conjugate gradient minimization. The 20 structures with the lowest target function values were selected, and subjected to an additional 2,000 steps of conjugate gradient energy minimization with restrained backbone atoms, using the CHARMM22 force field ${ }^{[35]}$ in NAMD, version 2.12 ${ }^{[36]}$. VMD (visual molecular dynamics), version $1.9 .3^{[37]}$, was used to analyse the final ensemble of 20 structures. The geometry, stereochemical quality and structural statistics of the final ensemble of structures was assessed and validated using PROCHECK ${ }^{[38]}$ and the wwPDB web service ${ }^{[39]}$.

\subsection{Molecular dynamics simulation}

Structural model coordinates of an SDS micelle were obtained from Jakobtorweihen et al. ${ }^{[40]}$, and used in the construction of an SDS micelle-peptide system, which was constructed by aligning the centres of mass of the micelle and the medoid palustrin-Ca structure with VMD. To ensure that the system's charge remained neutral, chloride ions were added as counter-ions, and finally, TIP3P water was used to solvate the system.

The system was energy minimized and equilibrated using the CHARMM22 all-atom forcefield ${ }^{[35,41]}$ within NAMD version $2.12^{[36]}$. All calculations were conducted within the NPT ensemble, using the Langevin piston Nose-Hoover $\operatorname{method}^{[42,43]}$ and periodic boundary conditions. Long-range non-bonded interactions were calculated up to a switching distance of $8.5 \AA$, beyond which a smooth switching function truncated the energy to a cut-off of $11 \AA$. The PME method ${ }^{[44]}$ was used to calculate long-range electrostatic interactions 
at each time step. The non-bonded interaction list was also updated every step. All bonds to hydrogen atoms were constrained using the SHAKE algorithm ${ }^{[45]}$. A 2 fs timestep was employed.

The solvated peptide-micelle system was minimized for 2,000 conjugate gradient steps with peptide backbone atoms fixed, and a further 2,000 steps with its $\alpha$-carbon atoms restrained. The system was then heated to a temperature of $310 \mathrm{~K}$ over 6,000 steps using Langevin dynamics, with $\alpha$-carbon remaining restrained. The system volume was equilibrated with the Langevin piston at $1 \mathrm{~atm}$ over 24,000 steps, with a further 24,000 steps without restraints. Finally, the system was simulated for 57.4 ns.

The radial distribution function $g(r)$ was used for analysing the final XX ns of simulation data. The measure gofr command within VMD was used to calculate the $g(r)$ function between each residue's carbon atoms and the SDS micelle's non-sulfate atoms. The default values 0.1 and $25.0 \AA$ were used for $\delta r$ and max $r$, respectively.

\section{Results and Discussion}

\subsection{Conformational analysis by NMR}

Two-dimensional NMR spectroscopy was used to determine the structure of palustrin-Ca in a 50:50 TFE- $d_{3} /$ water solvent mixture, which is known to promote the formation of secondary structural elements observed in biological membranes by enhancing the peptide's $\alpha$-helical character ${ }^{[46]}$. The collected spectra were well-resolved, with well-dispersed peaks that facilitated unambiguous resonance assignment. Individual residue spin systems were identified with the aid of TOCSY, ${ }^{1} \mathrm{H}_{-}{ }^{13} \mathrm{C}$ HSQC and ${ }^{1} \mathrm{H}_{-}{ }^{15} \mathrm{~N}$ HSQC spectra, while sequence-specific resonance assignment was conducted using the HN-HN and HN-H $\alpha$ regions of the NOESY spectrum. The first sequencespecific resonance assignments were made for the unique residues $\mathrm{Thr}^{9}$, Glu ${ }^{12}$ and $\mathrm{Val}^{15}$, with the remainder being assigned through the use of a backbonewalk, and investigation of $\mathrm{HN}-\mathrm{H} \alpha$ region peaks, where necessary. The Gly ${ }^{1}$ amide proton chemical shift could not be determined due to chemical exchange. The presence of a disulfide bridge was confirmed by observation of clear long-range $\beta_{i}-\beta_{i+6}$ nOe peaks between residues $\mathrm{Cys}^{23}{ }_{-} \mathrm{Cys}^{29}$. 


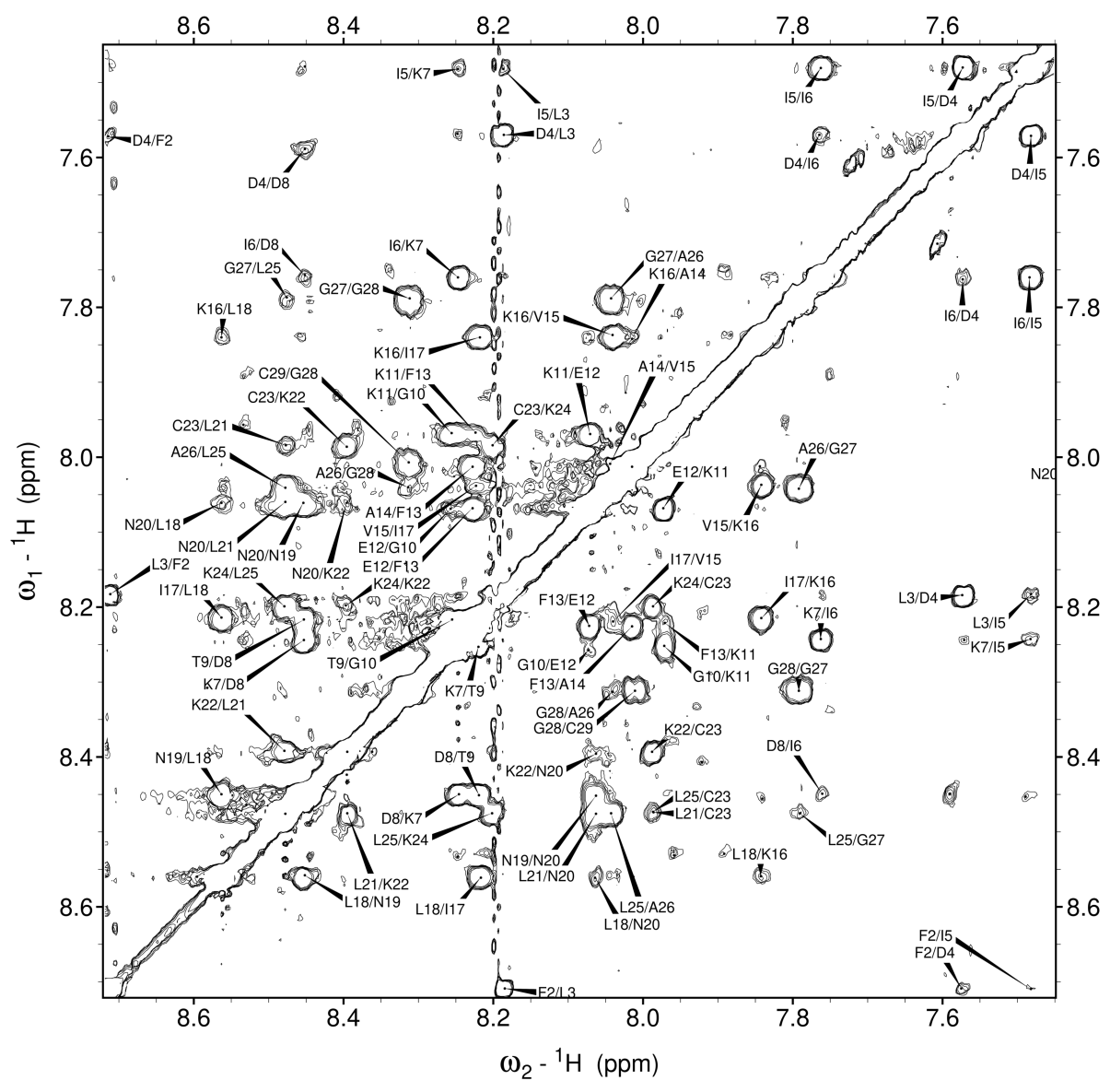

Figure 1: Amide region of the $200 \mathrm{~ms}$ NOESY spectrum of palustrin-Ca in $50 \%$ TFE- $d_{3}-\mathrm{H}_{2} \mathrm{O}$ mixed solvent system with $\mathrm{d}_{\mathrm{NN}}(i, i+1)$ connectivities labelled. 


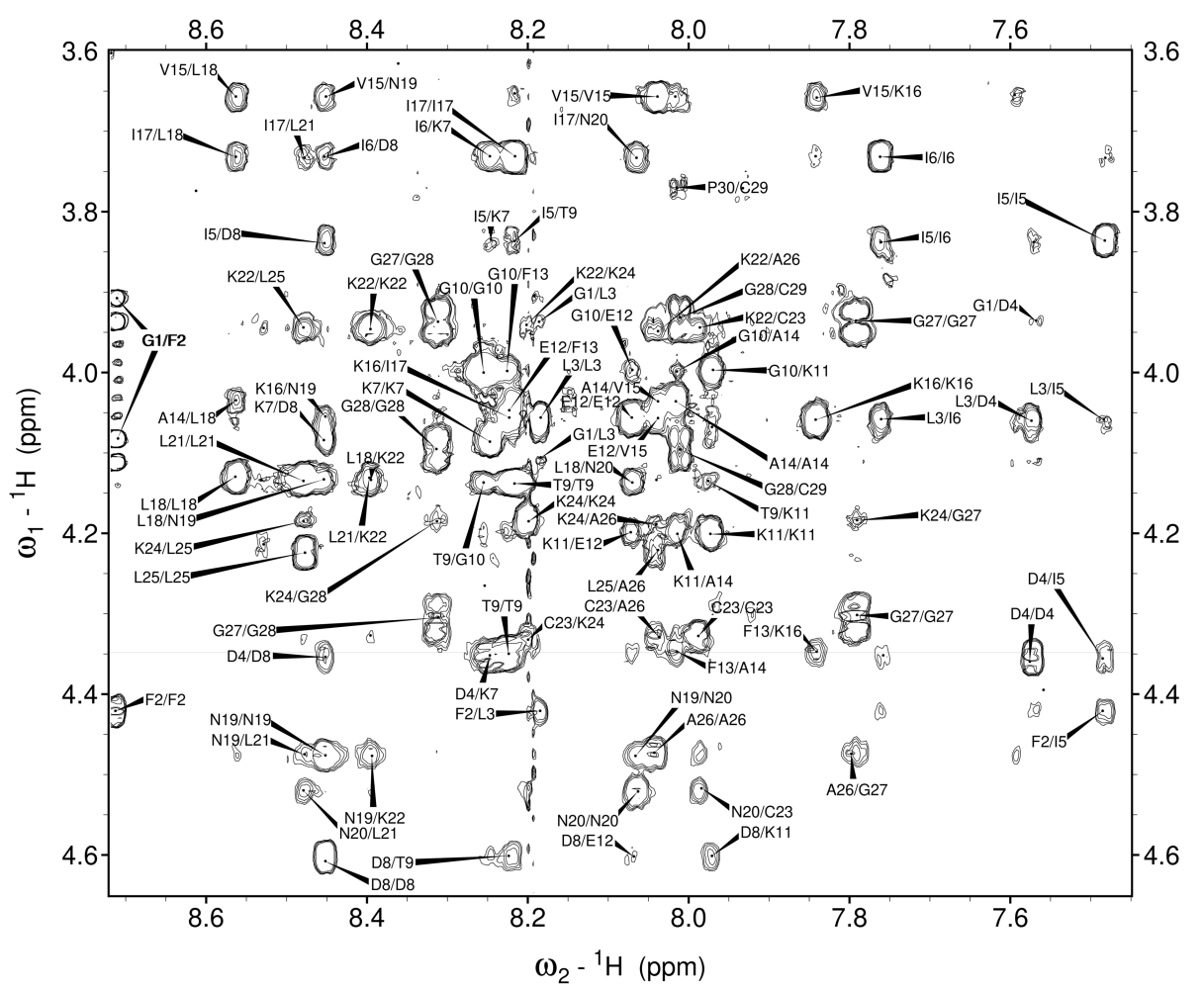

Figure 2: Fingerprint region of the $200 \mathrm{~ms}$ NOESY spectrum of palustrin$\mathrm{Ca}$ in $50 \%$ TFE- $d_{3}-\mathrm{H}_{2} \mathrm{O}$ mixed solvent system with backbone connectivities labelled.

All the ${ }^{1} \mathrm{H}$ chemical shifts identified for palustrin-Ca are detailed in Table 1. Likewise, all of palustrin-Ca's intermolecular nOe connectivities are summarised in Figure 3, where the nOe intensity is proportional to the thickness of each line. Multiple $\mathrm{d}_{\alpha \mathrm{N}}(\mathrm{i}, \mathrm{i}+3), \mathrm{d}_{\alpha \beta}(\mathrm{i}, \mathrm{i}+3), \mathrm{d}_{\alpha \mathrm{N}}(\mathrm{i}, \mathrm{i}+4)$ and $\mathrm{d}_{\alpha \beta}(\mathrm{i}, \mathrm{i}+4)$ were identified, which are indicative of an $\alpha$-helical secondary structure.

\subsection{Chemical shift analysis}

Amide proton chemical shift deviations, calculated as the difference between the observed chemical shift and the random coil chemical shift $(\Delta \delta=$ $\delta_{\text {obs }}-\delta_{r c}$ ), are connected with the hydrogen bond length ${ }^{[47]}$. Shorter hydrogen bond lengths are associated with higher $\Delta \delta$ values, and vice versa. Calculated amide proton chemical shift deviations are illustrated in Figure 4a; the corresponding hydrogen bond lengths are given in Figure 4b. The amide proton chemical shift deviations exhibit a periodicity of 3-5 from residue 8 on, with greater frequency in the $\mathrm{C}$-terminal part of the sequence. The greatest 
Table 1: ${ }^{1} \mathrm{H}$ chemical shifts (ppm) identified for every residue of palustrin-Ca in $50 \% \mathrm{TFE}-d_{3} / \mathrm{H}_{2} \mathrm{O}$

\begin{tabular}{|c|c|c|c|c|}
\hline Amino acid & $\mathrm{NH}$ & $\mathrm{H} \alpha$ & $\mathrm{H} \beta$ & Other protons \\
\hline Gly $^{1}$ & & $4.101,3.923$ & & \\
\hline $\mathrm{Phe}^{2}$ & 8.711 & 4.421 & $3.240,3.075$ & $\delta 7.235 ; \epsilon 7.321$ \\
\hline $\mathrm{Leu}^{3}$ & 8.185 & 4.059 & $1.683,1.569$ & $\gamma 1.634 ; \delta 0.972,0.920$ \\
\hline $\mathrm{Asp}^{4}$ & 7.573 & 4.356 & $2.880,2.777$ & \\
\hline $\operatorname{Ile}^{5}$ & 7.482 & 3.836 & 2.064 & $\gamma 1.251,0.917 ; \delta 0.922$ \\
\hline $\mathrm{Ile}^{6}$ & 7.761 & 3.731 & 1.970 & $\gamma 11.482,1.106 ; \gamma 20.893 ; \delta 0.808$ \\
\hline Lys $^{7}$ & 8.246 & 4.085 & 1.939 & $\gamma 1.666,1.486 ; \delta 1.733, \epsilon 2.980$ \\
\hline $\mathrm{Asp}^{8}$ & 8.452 & 4.603 & $3.075,2.941$ & \\
\hline Thr $^{9}$ & 8.219 & 4.351 & 4.136 & $\gamma 1.293$ \\
\hline Gly $^{10}$ & 8.254 & 3.998 & & \\
\hline $\operatorname{Lys}^{11}$ & 7.971 & 4.198 & 2.005 & $\gamma 1.655,1.525 ; \delta 1.764 ; \epsilon 3.021,3.005$ \\
\hline $\mathrm{Glu}^{12}$ & 8.070 & 4.056 & $2.288,2.172$ & $\gamma 2.606,2.457$ \\
\hline $\mathrm{Phe}^{13}$ & 8.226 & 4.348 & 3.272 & $\delta 7.277,7.291$ \\
\hline $\mathrm{Ala}^{14}$ & 8.014 & 4.035 & 1.587 & \\
\hline $\mathrm{Val}^{15}$ & 8.039 & 3.656 & 2.222 & $\gamma 1.125,0.989$ \\
\hline $\operatorname{Lys}^{16}$ & 7.841 & 4.059 & $2.058,1.964$ & $\gamma 1.478,1.449 ; \delta 1.716,1.676 ; \epsilon 3.007,2.994$ \\
\hline $\mathrm{Ile}^{17}$ & 8.217 & 3.732 & 1.979 & $\gamma 11.499,1.071 ; \gamma 20.888 ; \delta 0.725$ \\
\hline $\mathrm{Leu}^{18}$ & 8.561 & 4.132 & 1.925 & $\gamma 1.583 ; \delta 0.922$ \\
\hline $\operatorname{Asn}^{19}$ & 8.453 & 4.477 & $2.972,2.771$ & $\delta 6.588$ \\
\hline $\operatorname{Asn}^{20}$ & 8.063 & 4.521 & $3.051,2.831$ & $\delta 6.789$ \\
\hline $\mathrm{Leu}^{21}$ & 8.477 & 4.134 & $1.919,1.844$ & $\gamma 1.781 ; \delta 0.948,0.914$ \\
\hline $\operatorname{Lys}^{22}$ & 8.395 & 3.944 & 2.003 & $\gamma 1.455 ; \delta 1.720,1.673 ; \epsilon 2.978$ \\
\hline $\mathrm{Cys}^{23}$ & 7.987 & 4.328 & $3.472,3.185$ & \\
\hline $\operatorname{Lys}^{24}$ & 8.200 & 4.185 & $2.091,1.988$ & $\gamma 1.645,1.517 ; \delta 1.714$ \\
\hline $\mathrm{Leu}^{25}$ & 8.476 & 4.222 & 1.892 & $\gamma 1.544 ; \delta 0.906$ \\
\hline $\mathrm{Ala}^{26}$ & 8.040 & 4.471 & 1.546 & \\
\hline $\mathrm{Gly}^{27}$ & 7.791 & $4.304,3.936$ & & \\
\hline $\mathrm{Gly}^{28}$ & 8.312 & $4.091,3.936$ & & \\
\hline $\mathrm{Cys}^{29}$ & 8.012 & 4.970 & $3.377,2.951$ & \\
\hline Pro $^{30}$ & & 4.662 & $2.324,2.064$ & $\gamma 2.006 ; \delta 3.768,3.661$ \\
\hline $\operatorname{Pro}^{31}$ & & 4.391 & $2.313,2.058$ & $\gamma 2.010 ; \delta 3.766,3.622$ \\
\hline
\end{tabular}


$10 \quad 30$

GFLDIIKDTGKEFAVKILNNLKCKLAGGCP P

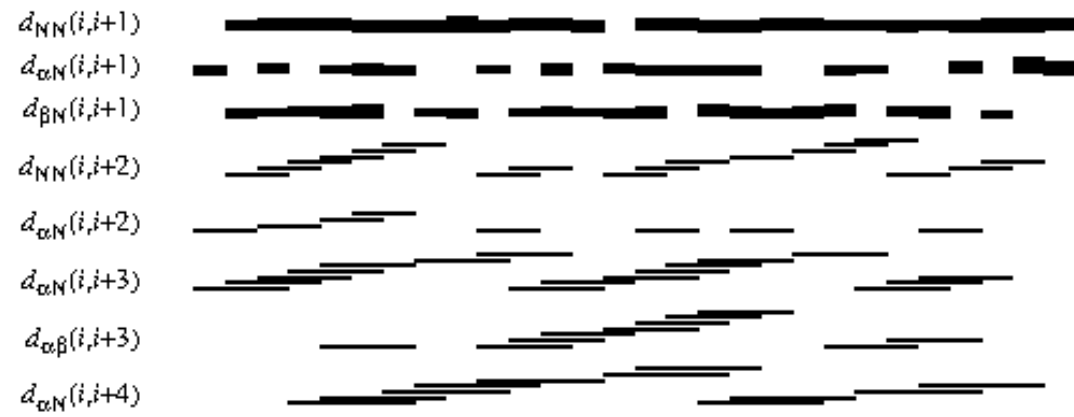

Figure 3: Short- and medium-range connectivities for palustrin-Ca in 50\% TFE- $d_{3}-\mathrm{H}_{2} \mathrm{O}$.
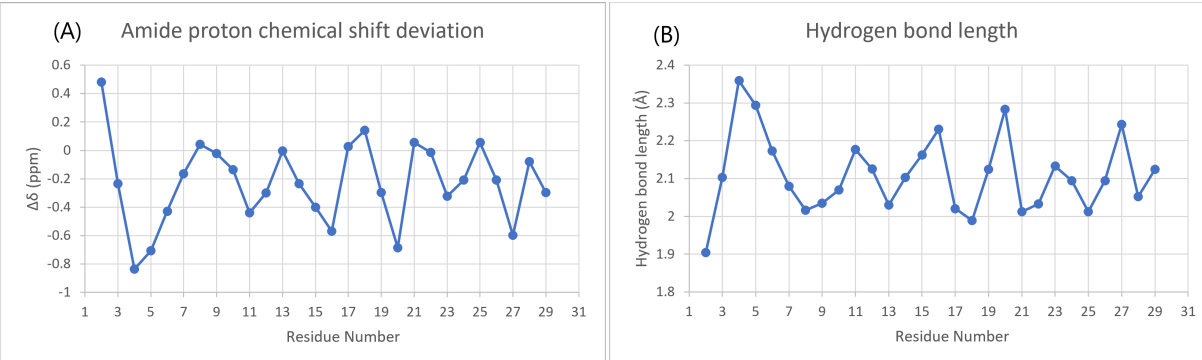

Figure 4: a Amide proton chemical shift deviation plot of palustrin-Ca in $50 \%$ TFE- $d_{3}-\mathrm{H}_{2} \mathrm{O}$. The observed amide proton chemical shifts were compared to the standard random coil chemical shifts $\left(\Delta \delta=\delta_{o b s}-\delta_{r c}\right.$. b Hydrogen bond distance as calculated from the chemical shift deviations $\left(\Delta \delta=19.2 d_{N}^{-3}-2.3\right)$, where $d_{N}$ denotes hydrogen bond length ${ }^{[47]}$.

values are found for the $\mathrm{Phe}^{2}, \mathrm{Asp}^{8}, \mathrm{Phe}^{13}, \mathrm{Leu}^{18}, \mathrm{Leu}^{21}, \mathrm{Leu}^{25}$ and $\mathrm{Gly}^{28}$, while the lowest values are observed for $\mathrm{Asp}^{4}, \mathrm{Lys}^{11}, \mathrm{Lys}^{16}, \mathrm{Asn}^{20}, \mathrm{Cys}^{23}$ and $\mathrm{Gly}^{27}$. As expected, the greatest values are observed for hydrophobic residues, with the exception of the $\mathrm{Asp}^{8}$ and $\mathrm{Gly}^{28}$ residues. Similarly, the lowest values are observed for polar and charged residues.

Similarly, $\alpha$-proton chemical shift deviations were calculated as the difference between the observed chemical shift and the random coil chemical shift $\left(\Delta \delta=\delta_{o b s}-\delta_{r c}\right)$. Four sequential $\alpha$-proton chemical shift deviations at least $0.1 \mathrm{ppm}$ lower than the expected random coil values indicate $\alpha$-helical segments, while three or more deviations at least $0.1 \mathrm{ppm}$ higher are indicative of $\beta$-strands; no change greater than $0.1 \mathrm{ppm}$ is indicative of coiled regions $^{[48]}$. Figure 5 shows the chemical shift deviations of palustrin-Ca, which 


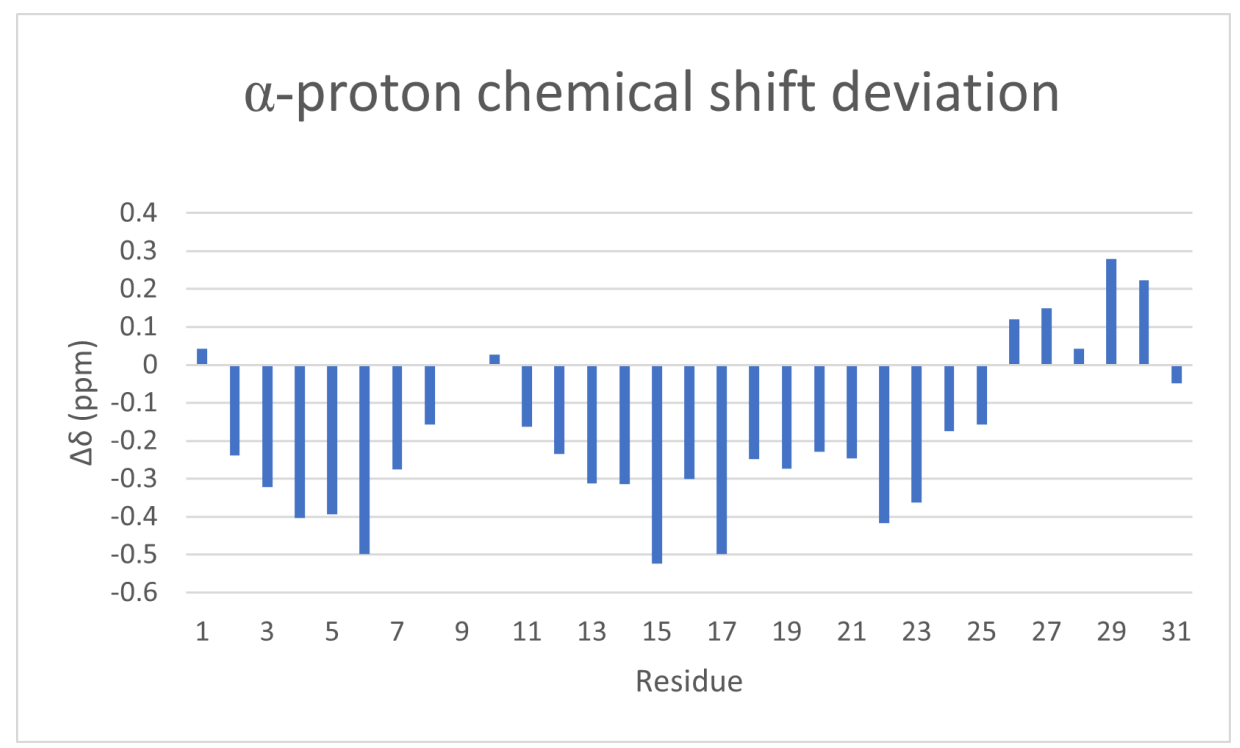

Figure 5: $\alpha$-proton chemical shift deviation plot of palustrin-Ca in 50\% TFE$d_{3}-\mathrm{H}_{2} \mathrm{O}$. The observed $\alpha$-proton chemical shifts were compared to the standard random coil chemical shifts $\left(\Delta \delta=\delta_{o b s}-\delta_{r c}\right.$.

shows a clear stretch of downfield shifts between residues 2-8, and again between residues 11-25. While these chemical shift deviations are indicative of $\alpha$-helical structure, the former stretch of downfield shifts may instead be attributed to a turn conformation.

\subsection{Molecular modelling}

The NOESY cross-peaks were integrated, and the resultant volumes were converted into distance restraints. CYANA was employed to generate one hundred structures, of which the twenty possessing the lowest target function values were further energy-minimized. Table 2 summarizes the structural and energetic statistics of the twenty selected models. As depicted in Figure 6 is predominantly $\alpha$-helical. The ensemble's secondary structural properties were analysed with the aid of STRIDE ${ }^{[49]}$. Most of the ensemble's structures are display $\alpha$-helical structures between residues $\mathrm{Ile}^{6}-\mathrm{Ala}^{26}$. The terminal segments are predominantly defined as turns, but possess significant coil character as well. 
Table 2: Mean structural statistics of the twenty structural models comprising the palustrin-Ca ensemble. The peptide structure has been deposited in the PDB with deposition code 7P4X. Model 10 is the representative medoid structure.

\begin{tabular}{ll}
\hline NOEs & \\
Intraresidue & 147 \\
Interresidue, sequential & 144 \\
Interresidue, nonsequential & 130 \\
\hline
\end{tabular}

Ensemble RMSD values, $\AA, \mathrm{SA} \pm \mathrm{SD}^{\mathrm{a}}$

\section{Backbone}

All residues

$1.270 \pm 0.418$

N-terminal segment (G1-I5)

$1.624 \pm 0.534$

Helix (I6-A26)

$0.754 \pm 0.181$

C-terminal segment (G27-P31)

$2.142 \pm 1.032$

\section{Heavy atoms}

All residues

$1.638 \pm 0.359$

N-terminal segment (G1-I5)

$2.073 \pm 0.447$

Helix (I6-A26)

$1.279 \pm 0.190$

C-terminal segment (G27-P31)

$2.397 \pm 1.175$

\section{Ramachandran plot analysis ${ }^{b}$}

Residues in most favoured regions

$84.2 \%$

Residues in additionally allowed regions

$9.6 \%$

Residues in generously allowed regions

$6.2 \%$

Residues in disallowed regions

$0 \%$

\begin{tabular}{ll}
\hline Average energies (kcal/mol) & \\
$\mathrm{E}_{\text {bond }}$ & 22.952 \\
$\mathrm{E}_{\text {angle }}$ & 134.653 \\
$\mathrm{E}_{\text {dihed }}$ & 91.179 \\
$\mathrm{E}_{\text {imprp }}$ & 5.888 \\
$\mathrm{E}_{\mathrm{VdW}}$ & -42.819 \\
$\mathrm{E}_{\text {elec }}$ & -501.612 \\
$\mathrm{E}_{\text {total }}$ & -292.328
\end{tabular}

${ }^{a}$ RMSD values from VMD

b Based on PROCHECK 


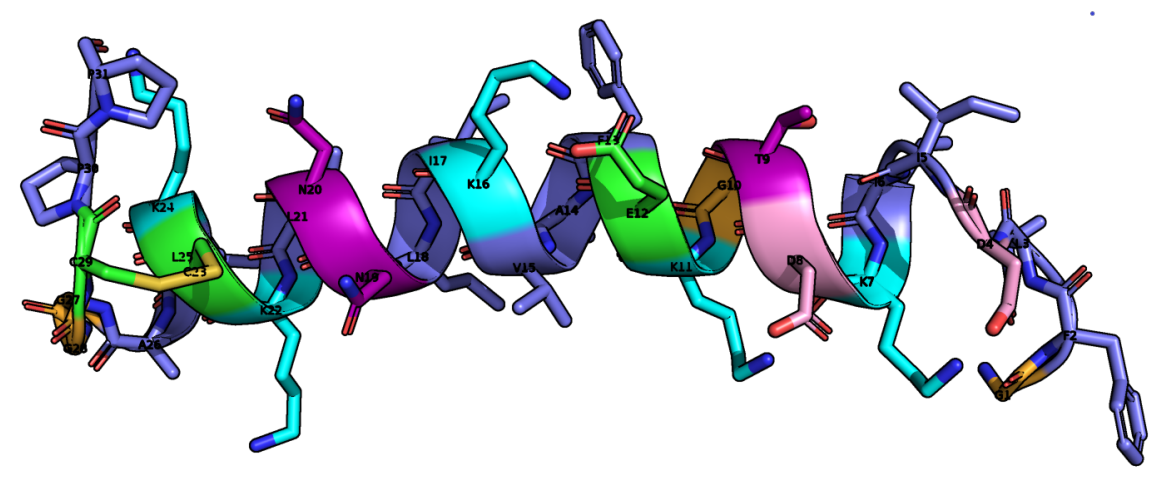

Figure 6: Ribbon representation of the medoid solution structure of palustrin$\mathrm{Ca}$ in $50 \%$ TFE- $\mathrm{d}_{3}-\mathrm{H}_{2} \mathrm{O}$. The amphipathic helical motif is observed. Positively charged residues are coloured in pink, negatively charged residues coloured in blue, polar residues coloured in purple, glycine residues coloured in orange, cysteine residues are coloured in green, hydrophobic residues coloured in slate.

\subsection{Molecular dynamics}

A molecular dynamics simulation of palustrin Ca's medoid structure in an SDS micelle was conducted to characterise its behaviour in the prokaryotic membrane-mimetic environment. In the course of the simulation, the peptide translocated from its initial position aligned with the micelle's centre of mass, to the micelle's surface-water boundary, where it adopted a position parallel to the micelle surface (Figure 7). The peptide's amphiphilicity is clearly apparent; its hydrophobic residues remain closely associated with the micellar interior, while the hydrophilic residues are in contact with the aqueous solvent and the micelle's anionic sulfate headgroups. This configuration is quite energetically favourable. 


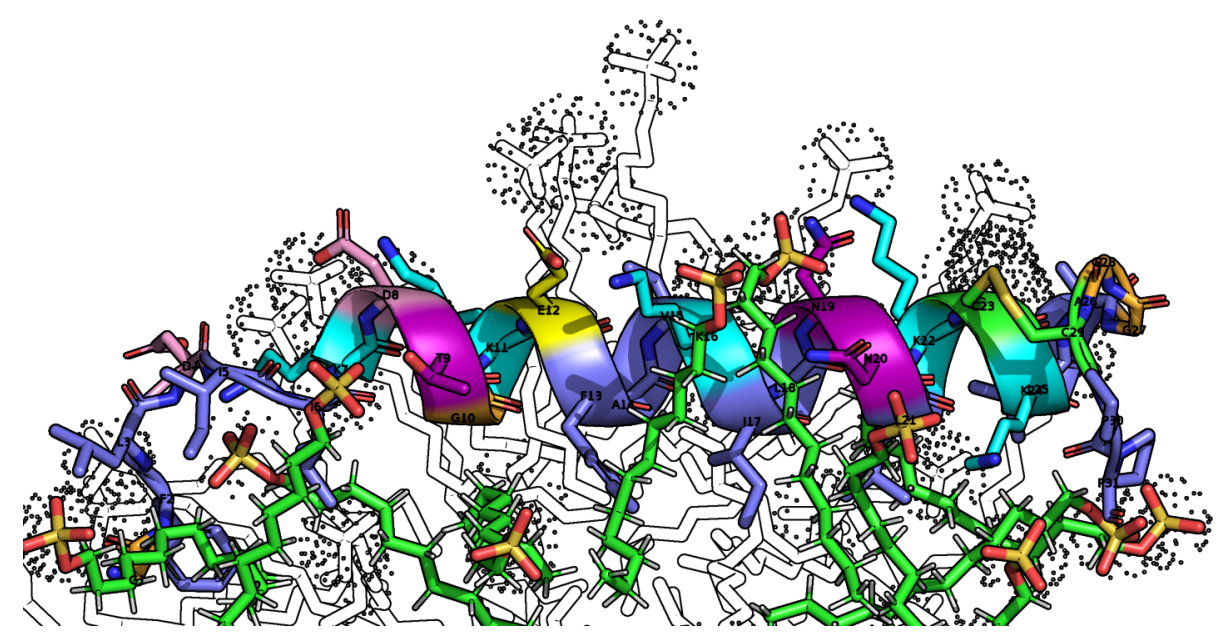

Figure 7: Palustrin-Ca positioned at the SDS micelle-water boundary. Lysine residue side chains are shown interacting with the negatively charged sulfate headgroups. Positively charged residues are coloured in pink, negatively charged residues coloured in blue, polar residues coloured in purple, glycine residues coloured in orange, cysteine residues are coloured in green, hydrophobic residues coloured in slate.

The peptide's interactions with the micelle's hydrophobic core were quantified using the radial distribution function $g(r)$, which was calculated between the peptide's carbon atoms and the micelle's aliphatic chain, and plotted against the radius $r$, as shown in Figure 8. 

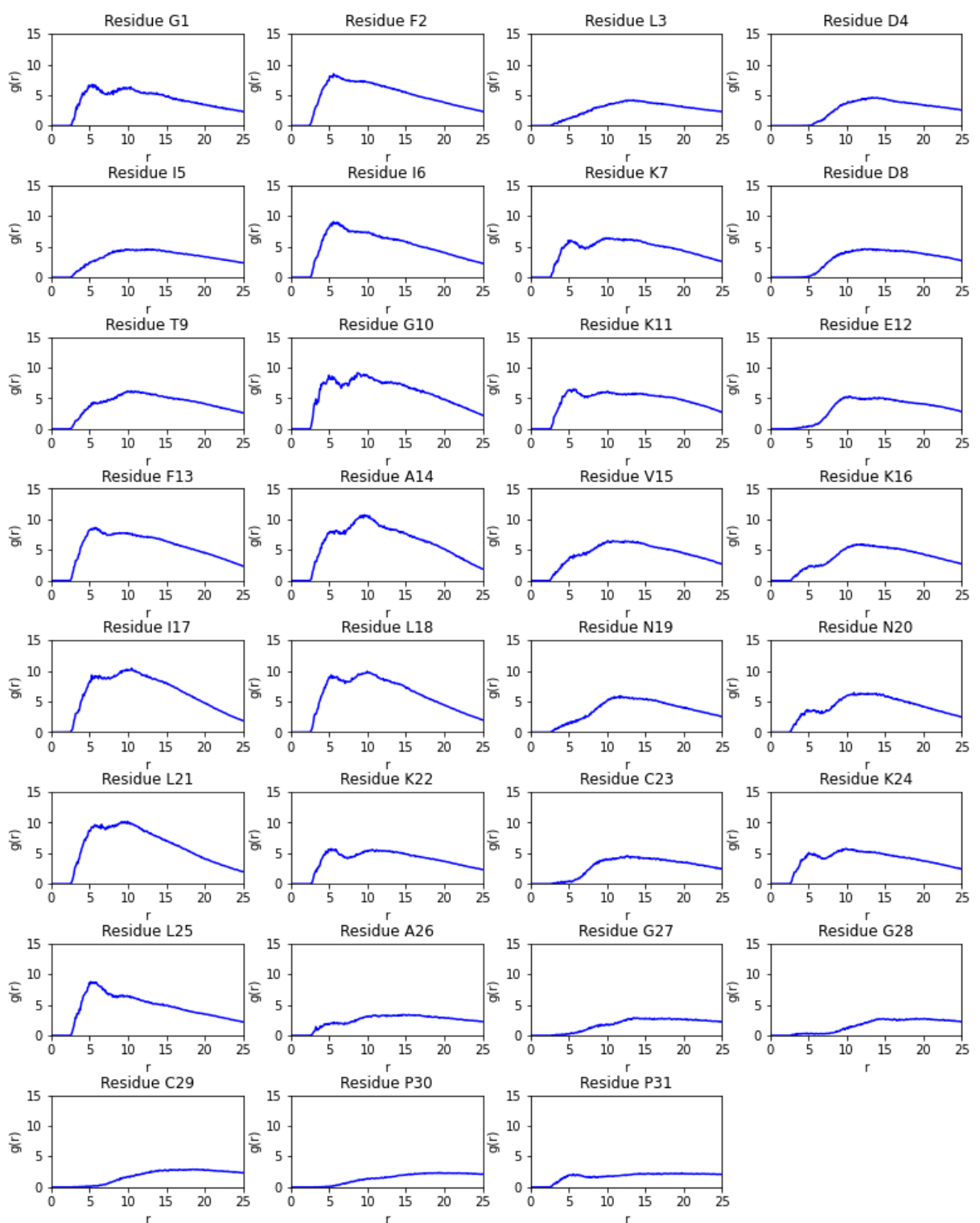

Figure 8: Radial distribution function (RDF) $g(r)$ plotted between palustrinCa's residues' carbon atoms and the sodium dodecyl sulfate (SDS) micelle aliphatic chain.

The radial distribution function plots illustrate clearly that the peptide's hydrophobic residues maintain a close association with the micelle, especially in the structured $\alpha$-helical segment. Interestingly, the N-terminal segment of the peptide is also found to maintain close association with the micelle, especially through the $\mathrm{Gly}^{1}$, $\mathrm{Phe}^{2}$ and $\mathrm{Ile}^{6}$ residues, despite the first five 
residues not forming part of a defined secondary structure. This is in contrast to the C-terminal segment, where beginning with $\mathrm{Ala}^{26}$ onwards the peptide is only weakly associated with the micelle.

The peptide, which was experimentally determined to be $\alpha$-helical $\mathrm{Ile}^{6}$ and $\mathrm{Ala}^{26}$, maintains this structure throughout the duration of the simulation. Despite the presence of a glycine residue at position 10, the $\alpha$-helix remains relatively rigid, not exhibiting any significant flexibility during the simulation. This suggests that the glycine residue occurs too far from the helical segment's middle to impart flexibility. Although studies have previously demonstrated that a rigid $\alpha$-helical structure can potentially result in an increased hemolytic activity ${ }^{[50]}$, this does not appear to apply in this case, which may be explained by the relatively flexible N-terminal and C-terminal segments, which combined account for 10 of the sequences 31 residues.

\section{Conclusion}

A number of biologically active peptides have been isolated from the American bullfrog Lithobates catesbeianus. The isolated peptides are diverse, and not limited to a single peptide family; palustrin-Ca is the only palustrin peptide isolated from this amphibian. Palustrin-Ca can be considered to be a member of the palustrin-2 family of peptides, sharing an average $42.09 \%$ sequence identity with 18 peptides of the palustrin- 2 family. Peptides that belong to the palustrin-2 family exhibit a variety of potent biological activities, including antimicrobial and anticancer activities, and therefore represent exciting candidates for novel drug development.

Palustrin-Ca is 31 amino acid residues long, of which 5 are lysine, 4 are glycine and 4 are leucine. The peptide has a cyclic disulphide-bridged heptapeptide domain at its C-terminus, which is conserved with other peptides of the palustrin-2 family.

This study employed NMR spectroscopy and molecular modelling methods to characterise the peptide's three-dimensional structure and obtain an ensemble of model structures. To date, palustrin-Ca is the only palustrin peptide to have had its three-dimensional structure elucidated. The results established that palustrin-Ca possesses an amphipathic, $\alpha$-helical structure between residues $\mathrm{Ile}^{6}-\mathrm{Ala}^{26}$ in a $50 \%$ TFE- $\mathrm{H}_{2} \mathrm{O}$ mixed solvent system, with the terminal segments predominantly defined as turns, with significant coil character as well.

A molecular dynamics simulation was conducted, whereby the medoid NMR-determined structure was simulated with an SDS micelle. The simulation results suggest that palustrin-Ca preferentially adopts a position parallel 
to the micelle's surface. This configuration is most energetically favourable as the peptide's hydrophobic residues can penetrate to the micelle's hydrophobic core, while the hydrophilic residues remain in contact with the aqueous solvent. The RDF plot in Figure 8 illustrates this clearly; the greatest values for $g(r)$ at small distances are observed for the hydrophobic Leu, Ile, Ala and Phe residues, demonstrating the importance of hydrophobicity for a peptide's ability to bind the target membrane. The observed preference for a position parallel to the micelle surface indicates that the peptide most probably exerts its antimicrobial activity through a non-pore-forming mechanism of action, such as the carpet model or the interfacial activity model.

This study's results will facilitate future work focused on investigating HDP structures, and their interactions with zwitterionic lipid bilayers, in order to further our understanding of the relationships between HDP structure and function. This study has extended earlier work from our research group that led to the elucidation of a number of host-defence peptide structures, and also complements related bioinformatic studies on peptide structure and function ${ }^{[51-54]}$.

\section{References}

[1] Xia X, Cheng L, Zhang S, Wang L, Hu J. The role of natural antimicrobial peptides during infection and chronic inflammation, 2018. doi:10.1007/s10482-017-0929-0.

[2] Maróti Gergely G, Kereszt A, Kondorosi É, Mergaert P. Natural roles of antimicrobial peptides in microbes, plants and animals. Research in Microbiology, 2011; 162(4): 363-374. doi:10.1016/j.resmic.2011.02.005.

[3] Avila EE. Functions of Antimicrobial Peptides in Vertebrates. Current Protein 85 Peptide Science, 2017; 18(11). doi:10.2174/ 1389203717666160813162629.

[4] da Silva Pereira L, do Nascimento VV, de Fátima Ferreira Ribeiro S, Rodrigues R, Fernandes KVS, de Oliveira Carvalho A, Vasconcelos IM, dos Santos Bento C, Sudré CP, Zottich U, Gomes VM. Characterization of Capsicum annuum L. leaf and root antimicrobial peptides: antimicrobial activity against phytopathogenic microorganisms. Acta Physiologiae Plantarum, 2018; 40(6): 107. doi:10.1007/s11738-018-2685-9.

[5] El Samak M, Solyman SM, Hanora A. Antimicrobial activity of bacteria isolated from Red Sea marine invertebrates. Biotechnology Reports, 2018; 19. doi:10.1016/j.btre.2018.e00275. 
[6] Gordon YJ, Romanowski EG, McDermott AM. Mini review: A review of antimicrobial peptides and their therapeutic potential as anti-infective drugs, 2005. doi:10.1080/02713680590968637.

[7] Tanphaichitr N, Srakaew N, Alonzi R, Kiattiburut W, Kongmanas K, Zhi R, Li W, Baker M, Wang G, Hickling D. Potential use of antimicrobial peptides as vaginal spermicides/microbicides. Pharmaceuticals, 2016; $9(1)$ : 13. doi:10.3390/ph9010013.

[8] Zhao RL, Han JY, Han WY, He HX, Ma JF. Effects of Two Novel Peptides from Skin of Lithobates Catesbeianus on Tumor Cell Morphology and Proliferation. In Molecular Cloning - Selected Applications in Medicine and Biology. InTech, 2011; doi:10.5772/25209.

[9] Lai R, Liu H, Hui Lee W, Zhang Y. An anionic antimicrobial peptide from toad Bombina maxima. Biochemical and Biophysical Research Communications, 2002; 295(4): 796-799. doi:10.1016/S0006-291X(02) 00762-3.

[10] Zelezetsky I, Tossi A. Alpha-helical antimicrobial peptides-Using a sequence template to guide structure-activity relationship studies, 2006. doi:10.1016/j.bbamem.2006.03.021.

[11] Xie J, Zhao Q, Li S, Yan Z, Li J, Li Y, Mou L, Zhang B, Yang W, Miao X, Jiang X, Wang R. Novel antimicrobial peptide CPF-C1 analogs with superior stabilities and activities against multidrug-resistant bacteria. Chemical Biology and Drug Design, 2017; 90(5): 690-702. doi:10.1111/ cbdd.12988.

[12] Yin LM, Edwards MA, Li J, Yip CM, Deber CM. Roles of hydrophobicity and charge distribution of cationic antimicrobial peptides in peptidemembrane interactions. Journal of Biological Chemistry, 2012; 287(10): 7738-7745. doi:10.1074/jbc.M111.303602.

[13] Son M, Lee Y, Hwang H, Hyun S, Yu J. Disruption of interactions between hydrophobic residues on nonpolar faces is a key determinant in decreasing hemolysis and increasing antimicrobial activities of $\alpha$-helical amphipathic peptides. ChemMedChem, 2013; 8(10): 1638-1642. doi: 10.1002/cmdc.201300264.

[14] Beveridge TJ. Structures of gram-negative cell walls and their derived membrane vesicles. Journal of Bacteriology, 1999; 181 (16): 4725-4733. doi:10.1128/jb.181.16.4725-4733.1999. 
[15] Weidenmaier C, Peschel A. Teichoic acids and related cell-wall glycopolymers in Gram-positive physiology and host interactions, 2008. doi:10.1038/nrmicro1861.

[16] Yeaman MR, Yount NY. Mechanisms of antimicrobial peptide action and resistance. Pharmacological Reviews, 2003; 55(1): 27-55. doi: 10.1124/pr.55.1.2.

[17] Perron GG, Zasloff M, Bell G. Experimental evolution of resistance to an antimicrobial peptide. Proceedings of the Royal Society B: Biological Sciences, 2006; 273(1583): 251-256. doi:10.1098/rspb.2005.3301.

[18] Sani MA, Henriques ST, Weber D, Separovic F. Bacteria may cope differently from similar membrane damage caused by the Australian tree frog antimicrobial peptide maculatin 1.1. Journal of Biological Chemistry, 2015; 290(32): 19853-19862. doi:10.1074/jbc.M115.643262.

[19] Brogden KA. Antimicrobial peptides: Pore formers or metabolic inhibitors in bacteria?, 2005. doi:10.1038/nrmicro1098.

[20] Shai Y. Mode of action of membrane active antimicrobial peptides, 2002. doi:10.1002/bip.10260.

[21] Subasinghage AP, Conlon JM, Hewage CM. Conformational analysis of the broad-spectrum antibacterial peptide, ranatuerin-2CSa: Identification of a full length helix-turn-helix motif. Biochimica et Biophysica Acta - Proteins and Proteomics, 2008; 1784(6): 924-929. doi: 10.1016/j.bbapap.2008.02.019.

[22] Subasinghage AP, Conlon JM, Hewage CM. Development of potent anti-infective agents from Silurana tropicalis: Conformational analysis of the amphipathic, alpha-helical antimicrobial peptide XT-7 and its non-haemolytic analogue [G4K]XT-7. Biochimica et Biophysica Acta - Proteins and Proteomics, 2010; 1804(4): 1020-1028. doi:10.1016/j. bbapap.2010.01.015.

[23] Subasinghage AP, O'Flynn D, Conlon JM, Hewage CM. Conformational and membrane interaction studies of the antimicrobial peptide alyteserin-1c and its analogue [E4K]alyteserin-1c. Biochimica et Biophysica Acta - Biomembranes, 2011; 1808(8): 1975-1984. doi: 10.1016/j.bbamem.2011.04.012. 
[24] Timmons PB, O'Flynn D, Conlon JM, Hewage CM. Structural and positional studies of the antimicrobial peptide brevinin-1BYa in membranemimetic environments. Journal of Peptide Science, 2019; 25(11): e3208. doi:10.1002/psc.3208.

[25] Timmons PB, O’Flynn D, Conlon JM, Hewage CM. Insights into conformation and membrane interactions of the acyclic and dicarba-bridged brevinin-1BYa antimicrobial peptides. European Biophysics Journal, 2019; 48(8): 701-710. doi:10.1007/s00249-019-01395-y.

[26] Benetti S, Timmons PB, Hewage CM. NMR model structure of the antimicrobial peptide maximin 3. European Biophysics Journal, 2019; 48(2): 203-212. doi:10.1007/s00249-019-01346-7.

[27] Timmons PB, Hewage CM. Biophysical study of the structure and dynamics of the antimicrobial peptide maximin 1. Journal of Peptide Science, 2021; (under consideration).

[28] Bax A, Davis DG. MLEV-17-based two-dimensional homonuclear magnetization transfer spectroscopy. Journal of Magnetic Resonance (1969), 1985; 65(2): 355-360. doi:10.1016/0022-2364(85)90018-6.

[29] Kumar A, Ernst RR, Wüthrich K. A two-dimensional nuclear Overhauser enhancement (2D NOE) experiment for the elucidation of complete proton-proton cross-relaxation networks in biological macromolecules. Topics in Catalysis, 1980; 95(1): 1-6. doi:10.1016/ 0006-291X(80)90695-6.

[30] John BK, Plant D, Webb P, Hurd RE. Effective combination of gradients and crafted RF pulses for water suppression in biological samples. Journal of Magnetic Resonance (1969), 1992; 98(1): 200-206. doi: 10.1016/0022-2364(92)90125-Q.

[31] Lee W, Tonelli M, Markley JL. NMRFAM-SPARKY: Enhanced software for biomolecular NMR spectroscopy. Bioinformatics, 2015; 31 (8): 1325-1327. doi:10.1093/bioinformatics/btu830.

[32] Güntert P, Braun W, Wüthrich K. Efficient computation of threedimensional protein structures in solution from nuclear magnetic resonance data using the program DIANA and the supporting programs CALIBA, HABAS and GLOMSA. Journal of Molecular Biology, 1991; 217(3): 517-530. doi:10.1016/0022-2836(91)90754-T. 
[33] Güntert P, Mumenthaler C, Wüthrich K. Torsion angle dynamics for NMR structure calculation with the new program DYANA. Journal of Molecular Biology, 1997; 273(1): 283-298. doi:10.1006/jmbi.1997.1284.

[34] Güntert P, Buchner L. Combined automated NOE assignment and structure calculation with CYANA. Journal of Biomolecular NMR, 2015; 62(4): 453-471. doi:10.1007/s10858-015-9924-9.

[35] Mackerell AD, Feig M, Brooks CL. Extending the treatment of backbone energetics in protein force fields: Limitations of gas-phase quantum mechanics in reproducing protein conformational distributions in molecular dynamics simulation. Journal of Computational Chemistry, 2004; 25(11): 1400-1415. doi:10.1002/jcc.20065.

[36] Phillips JC, Braun R, Wang W, Gumbart J, Tajkhorshid E, Villa E, Chipot C, Skeel RD, Kalé L, Schulten K. Scalable molecular dynamics with NAMD. Journal of Computational Chemistry, 2005; 26(16): 17811802. doi:10.1002/jcc.20289.

[37] Humphrey W, Dalke A, Schulten K. VMD: Visual molecular dynamics. Journal of Molecular Graphics, 1996; 14(1): 33-38. doi: 10.1016/0263-7855(96)00018-5.

[38] Laskowski RA, MacArthur MW, Moss DS, Thornton JM. PROCHECK: a program to check the stereochemical quality of protein structures. Journal of Applied Crystallography, 1993; 26(2): 283-291. doi:10.1107/ s0021889892009944.

[39] Berman H, Henrick K, Nakamura H. Announcing the worldwide Protein Data Bank, 2003. doi:10.1038/nsb1203-980.

[40] Jakobtorweihen S, Ingram T, Smirnova I. Combination of COSMOmic and molecular dynamics simulations for the calculation of membranewater partition coefficients. Journal of Computational Chemistry, 2013; 34(15): 1332-1340. doi:10.1002/jcc.23262.

[41] MacKerell AD, Bashford D, Bellott M, Dunbrack RL, Evanseck JD, Field MJ, Fischer S, Gao J, Guo H, Ha S, Joseph-McCarthy D, Kuchnir L, Kuczera K, Lau FT, Mattos C, Michnick S, Ngo T, Nguyen DT, Prodhom B, Reiher WE, Roux B, Schlenkrich M, Smith JC, Stote R, Straub J, Watanabe M, Wiórkiewicz-Kuczera J, Yin D, Karplus M. Allatom empirical potential for molecular modeling and dynamics studies of proteins. Journal of Physical Chemistry B, 1998; 102(18): 3586-3616. doi:10.1021/jp973084f. 
[42] Martyna GJ, Tobias DJ, Klein ML. Constant pressure molecular dynamics algorithms. The Journal of Chemical Physics, 1994; $101(5)$ : 4177-4189. doi:10.1063/1.467468.

[43] Feller SE, Zhang Y, Pastor RW, Brooks BR. Constant pressure molecular dynamics simulation: The Langevin piston method. The Journal of Chemical Physics, 1995; 103(11): 4613-4621. doi:10.1063/1.470648.

[44] Darden T, York D, Pedersen L. Particle mesh Ewald: An N·log(N) method for Ewald sums in large systems. The Journal of Chemical Physics, 1993; 98(12): 10089-10092. doi:10.1063/1.464397.

[45] Ryckaert JP, Ciccotti G, Berendsen HJ. Numerical integration of the cartesian equations of motion of a system with constraints: molecular dynamics of n-alkanes. Journal of Computational Physics, 1977; 23(3): 327-341. doi:10.1016/0021-9991(77)90098-5.

[46] Shiraki K, Nishikawa K, Goto Y. Trifluoroethanol-induced Stabilization of the $\alpha$-Helical Structure of $\beta$-Lactoglobulin: Implication for Non-hierarchical Protein Folding. Journal of Molecular Biology, 1995; 245(2): 180-194. doi:10.1006/jmbi.1994.0015.

[47] Wagner G, Pardi A, Wüthrich K. Hydrogen Bond Length and 1H NMR Chemical Shifts in Proteins. Journal of the American Chemical Society, 1983; 105 (18): 5948-5949. doi:10.1021/ja00356a056.

[48] Wishart DS, Sykes BD, Richards FM. The Chemical Shift Index : A Fast and Simple Method for the Assignment of Protein Secondary Structure Through NMR Spectroscopy. Biochemistry, 1992; 31(6): 1647-1651. doi:10.1021/bi00121a010.

[49] Frishman D, Argos P. Knowledge-based protein secondary structure assignment. Proteins: Structure, Function, and Bioinformatics, 1995; 23(4): 566-579. doi:10.1002/prot.340230412.

[50] Idiong G, Won A, Ruscito A, Leung BO, Hitchcock AP, Ianoul A. Investigating the effect of a single glycine to alanine substitution on interactions of antimicrobial peptide latarcin $2 \mathrm{a}$ with a lipid membrane. European Biophysics Journal, 2011; 40(9): 1087-1100. doi: 10.1007/s00249-011-0726-z.

[51] Timmons PB, Hewage CM. HAPPENN is a novel tool for hemolytic activity prediction for therapeutic peptides which employs neural 
networks. Scientific Reports, 2020; 10(1): 10869. doi:10.1038/ s41598-020-67701-3.

[52] Timmons PB, Hewage CM. ENNAACT is a novel tool which employs neural networks for anticancer activity classification for therapeutic peptides. Biomedicine and Pharmacotherapy, 2021; 133: 111051. doi: 10.1016/j.biopha.2020.111051.

[53] Timmons PB, Hewage CM. ENNAVIA is an innovative new method which employs neural networks for antiviral and anti-coronavirus activity prediction for therapeutic peptides. Briefings in Bioinformatics, 2021; 22: bbab258. doi:10.1093/bib/bbab258.

[54] Timmons PB, Hewage CM. APPTEST is a novel protocol for the automatic prediction of peptide tertiary structures. Briefings in Bioinformaticss, 2021; 22: bbab308. doi:10.1093/bib/bbab308. 